\title{
Gender differences in the association between childhood abuse and psychosis
}

Helen Fisher, Craig Morgan, Paola Dazzan, Thomas K. Craig, Kevin Morgan, Gerard Hutchinson, Peter B. Jones, Gillian A. Doody, Carmine Pariante, Peter McGuffin, Robin M. Murray, Julian Leff and Paul Fearon

\section{Background}

Studies demonstrating an association between childhood trauma and psychosis in adulthood have not systematically explored gender differences.

\section{Aims \\ To investigate gender differences in the prevalence of childhood sexual and physical abuse among people with psychosis in comparison with healthy controls.}

\section{Method}

The Childhood Experiences of Care and Abuse Questionnaire was completed to elicit experiences of sexual and physical abuse during childhood in first-episode psychosis cases and population-based controls.

\section{Results}

Among women, those in the cases group were twice as likely to report either physical or sexual abuse compared with controls following adjustment for all confounders. In particular, the effect of physical abuse in women was stronger and more robust than that for sexual abuse. A similar trend was found for psychotic-like experiences in the female control group. No association was found in men.

\section{Conclusions}

Reports of severe childhood physical or sexual abuse were associated with psychosis in women but not in men.

\section{Declaration of interest}

None.
Recently interest has been renewed in the controversial question of whether childhood trauma increases risk of psychosis in adulthood. Several large population-based studies have found associations between various types of early trauma and psychosis-like experiences in adulthood, ${ }^{1-3}$ and others have reported a relatively high prevalence of childhood abuse in samples of patients with psychotic symptoms. ${ }^{4,5}$ This has led some to claim that childhood adversity is a cause of psychosis in adulthood. ${ }^{6}$ However, the evidence to support a causal link is inconsistent, and suffers from conceptual and methodological problems, including the use of crude measures of early abuse and limited use of healthy comparison groups. ${ }^{7,8}$ Moreover, previous studies have not systematically explored the association between childhood trauma and psychosis by gender, ${ }^{7}$ despite evidence from other disorders suggesting that the prevalence and impact of such experiences on later psychopathology differs between men and women. ${ }^{9,10}$ Indeed, in a recent review of the published literature we reported that rates of childhood trauma also differed by gender among patients with a psychotic disorder. ${ }^{8}$ Therefore, using data collected as part of a large epidemiological case-control study of first-episode psychosis, we sought to test the hypothesis that childhood sexual and physical abuse is associated with risk of psychosis and that this effect would differ between men and women.

\section{Method}

This study forms part of the Aetiology and Ethnicity in Schizophrenia and Other Psychoses (ÆSOP) study and full details of the study method, including recruitment and inclusion and exclusion criteria, have been published previously. ${ }^{11}$

\section{Participants}

The inclusion criteria for cases were age 16-64 years, residence within defined catchment areas in south-east London and Nottingham, presence of a first episode of psychosis (ICD-10 codes F20-F29 and F30-F33) ${ }^{12}$ within the time frame of the study (1997-2000) and no previous contact with health services for psychosis. Exclusion criteria were evidence of psychotic symptoms precipitated by an organic cause, and transient psychotic symptoms resulting from acute intoxication as defined by ICD-10. The inclusion of only those who met criteria for a diagnosis of psychosis ruled out the possibility that symptoms were subclinical or resulted from another disorder such as post-traumatic stress disorder.

For the control group a random sample of individuals aged 16-64 years were recruited from the population of the same geographical areas as the cases group. The sampling procedure was adapted from that used by the Office of Population and Census Statistics Psychiatric Morbidity Survey. ${ }^{13}$ To ensure that a sufficient number of people of Black Caribbean ethnicity were recruited as controls, we purposely oversampled this population by continuing recruitment for a longer period. The Psychosis Screening Questionnaire (PSQ) ${ }^{14}$ was administered to all potential control group participants; individuals were excluded if they screened positive on the PSQ and were found to have a clinical psychotic disorder.

\section{Procedures}

All participants who consented completed the Childhood Experiences of Care Abuse Questionnaire (CECA.Q). ${ }^{15}$ This is a self-report measure designed to elicit information concerning childhood experiences before the age of 17 years, including physical abuse by the main mother and father figures during childhood (usually but not necessarily the biological parents), and sexual abuse by any adult or an individual at least 5 years older than the recipient. Because of the inclusion criteria for this study, only incidences of abuse before age 16 years were included. Both the physical and sexual abuse sections of the CECA.Q begin with screening questions and then positive responses are followed up with more detailed questions. The CECA.Q elicits concrete examples of adverse experiences, and a guide has been published 
to score the severity of the responses in a standardised manner. ${ }^{15}$ These factors ensure that the validity of the self-reported experiences is enhanced. ${ }^{16}$ Furthermore, this measure has been shown to have satisfactory levels of test-retest reliability and concurrent validity. ${ }^{15,17}$ This questionnaire was read out to all participants to improve the accuracy of the fixed category responses obtained.

Data on age, gender and ethnicity were obtained using the Medical Research Council Socio-demographic Schedule. ${ }^{18}$ Ethnicity was self-ascribed and standardised using the 11 categories employed by the UK census in 2001. The Family Interview for Genetic Studies (FIGS) ${ }^{19}$ was used to obtain information from a key informant about the participant's family history of mental health problems. For those in the cases group this interview was supplemented by information retrieved from case notes. The presence or absence of a positive history in either parent of any ICD-10 psychiatric diagnosis was determined through consensus meetings by two consultant psychiatrists using data obtained from the FIGS.

Symptom data were collected on patients using the Schedules for Clinical Assessment in Neuropsychiatry (SCAN), ${ }^{20}$ and ICD-10 diagnoses were determined using the SCAN data on the basis of consensus meetings involving one of the ÆSOP study's principal investigators (J.L., R.M., P.J.) and other members of the research team. Diagnoses were made masked to ethnicity and abuse history. Full details can be found in the report by Kirkbride et al. ${ }^{21}$

Data on subclinical psychosis-like symptoms in the past year were obtained from controls using the PSQ. Endorsement of one or more symptoms (hypomania, thought insertion, paranoia, strange experiences, hallucinations) using the criteria outlined by Johns et al was considered to indicate the presence of psychoticlike experiences. ${ }^{22}$

\section{Analysis}

For the analyses, the most conservative cut-off points published by Bifulco et al were used to dichotomise responses on the CECA.Q into severe and non-severe categories for each maltreatment variable. ${ }^{15}$ A composite variable was also computed to summarise the experience of sexual and physical trauma ('physical and/or sexual'), comprising three categories of reported abuse: none (0), either physical or sexual abuse (1) and both physical and sexual abuse (2). Physical abuse was defined as repeated exposure to physical violence from either the main mother or father figure before age 16 years. In order to be considered 'severe' these incidents had to meet at least two of the following criteria:

(a) the abuse consisted of being hit with a belt or stick, or being punched or kicked;

(b) the abuse resulted in an injury, including broken limbs, black eyes or bruising;

(c) the perpetrator was considered to be out of control.

Mild forms of punishment such as being smacked or hit with a slipper were excluded. Sexual abuse was considered to be unwanted sexual experiences prior to age 16 years and was not limited to the immediate family. To be defined as 'severe' these experiences had to meet at least two of the following criteria:

(a) the perpetrator was known to the individual;

(b) the perpetrator was a relative;

(c) the perpetrator lived in the same household;

(d) the unwanted sexual experience occurred more than once;

(e) the perpetrator touched the child's genitals; (f) the perpetrator forced the child to touch the perpetrator's genitals;

(g) the abuse involved sexual intercourse.

Exposure by a stranger without any physical contact was excluded.

Logistic regression was used to analyse the relationship between each form of maltreatment and case-control status or presence of psychotic-like experiences, while controlling for potential confounders. This was done first with the sample unstratified, and then stratified by gender to investigate the main study hypotheses following likelihood ratio tests to determine interaction effects. A more liberal $P$ value of 0.10 was employed for the interaction tests, as such effects are extremely difficult to detect. All analyses were weighted to correct for the oversampling of Black Caribbean participants in the control group (see Morgan et al for full details). ${ }^{23}$ In all logistic regressions, age (16-35 or 36-64 years), ethnicity (White British, mixed, Indian, Pakistani, Bangladeshi, other Asian, Black Caribbean, Black African, Black other, Chinese or other), study centre (London or Nottingham) and parental history of mental illness (present or absent) were controlled. These adjusted odds ratios are presented with and without parental mental illness controlled, to allow the specific confounding or potential moderating effects of this variable (which has previously been strongly associated with childhood abuse $)^{24}$ to be assessed. All analyses were conducted using Stata version 8 for Windows.

\section{Results}

A total of 390 people in the cases group and 391 people in the control group were successfully recruited to the case-control arms of the ÆSOP study in the south-east London and Nottingham sites. ${ }^{23}$ Of these, 181 in the cases group and 246 in the control group completed the CECA.Q and were included in the following analyses. Those who completed the CECA.Q did not differ significantly from those who did not in terms of gender, age or ethnicity (data, not shown, are available from the authors). The majority of those in the cases group (61\%) had a non-affective psychotic diagnosis. The basic demographic data by case and control status for those included in the analyses are presented in Table 1. Compared with the control group, and in line with what would be expected, participants in the cases group were younger $(P<0.001)$, more often men $(P<0.05)$, more often of non-White ethnicity $(P<0.001)$, and more often reported a parental history of mental illness $(P<0.001)$. There were more controls from Nottingham than London $(P<0.05$; Table 1$)$. All these variables were therefore controlled for in subsequent analyses.

Compared with controls, those in the cases group were approximately twice as likely to report experiences of physical abuse before the age of 16 years $(P<0.01)$. However, when adjusted for age, study centre and ethnicity, this association was attenuated $(P=0.071)$. Further controlling for parental mental illness did not suggest significant additional confounding by this variable (Table 2). Childhood sexual abuse was marginally more common in cases than controls but did not reach standard levels of statistical significance (Table 2). Reports of either physical or sexual abuse during childhood were marginally more common in cases than controls for the full sample, but this difference failed to reach statistical significance $(P=0.123)$. There was an even greater risk of psychosis if the participant had experienced both physical and sexual abuse, but this association was non-significant $(P=0.067)$ owing to the small number of individuals reporting this combination of traumatic experiences $(n=25 / 411)$ (Table 2). 


\begin{tabular}{|c|c|c|c|c|c|}
\hline & $\begin{array}{c}\text { Cases } \\
(n=181)\end{array}$ & $\begin{array}{c}\text { Controls } \\
(n=246)\end{array}$ & Test & d.f. & $P$ \\
\hline $\begin{array}{l}\text { Gender, } n(\%) \\
\quad \text { Male } \\
\text { Female }\end{array}$ & $\begin{array}{l}97(54) \\
84(46)\end{array}$ & $\begin{array}{l}103(42) \\
143(58)\end{array}$ & $\chi^{2}=5.292$ & 1 & $0.02^{*}$ \\
\hline $\begin{array}{l}\text { Ethnicity, } n(\%)^{a} \\
\text { White British } \\
\text { Black Caribbean } \\
\text { Other }\end{array}$ & $\begin{array}{r}101(56) \\
36(20) \\
44(24)\end{array}$ & $\begin{array}{r}181(74) \\
35(14) \\
30(12)\end{array}$ & $\chi^{2}=15.830$ & 2 & $<0.001^{* *}$ \\
\hline $\begin{array}{l}\text { Study centre, } n(\%) \\
\quad \text { London } \\
\text { Nottingham }\end{array}$ & $\begin{array}{l}82(45) \\
99(55)\end{array}$ & $\begin{array}{r}81(33) \\
165(67)\end{array}$ & $\chi^{2}=6.254$ & 1 & $0.01^{*}$ \\
\hline $\begin{array}{l}\text { Parental mental illness, } n(\%)^{b} \\
\text { Any } \\
\text { None }\end{array}$ & $\begin{array}{r}34(21) \\
127(79)\end{array}$ & $\begin{array}{c}8(3) \\
238(97)\end{array}$ & $\chi^{2}=31.661$ & 1 & $<0.001^{* *}$ \\
\hline Age, years: mean (s.d.) & $31(11.3)$ & $39(12.7)$ & $t=6.434$ & 425 & $<0.001^{* *}$ \\
\hline
\end{tabular}

\begin{tabular}{|c|c|c|c|c|c|c|c|c|}
\hline Type of abuse & $\begin{array}{c}\text { Cases } \\
(n=181) \\
n(\%)\end{array}$ & $\begin{array}{c}\text { Controls } \\
(n=246) \\
n(\%)\end{array}$ & $\begin{array}{c}\text { Unadjusted } \\
\mathrm{OR}^{\mathrm{a}} \\
(95 \% \mathrm{Cl})\end{array}$ & $P$ & $\begin{array}{c}\text { Adjusted } \mathrm{OR}^{\mathrm{a}, \mathrm{b}} \\
(95 \% \mathrm{Cl})\end{array}$ & $P$ & $\begin{array}{c}\text { Adjusted OR } \mathrm{R}^{\mathrm{a}, \mathrm{c}} \\
(95 \% \mathrm{Cl})\end{array}$ & $P$ \\
\hline \multicolumn{9}{|l|}{ Physical abuse } \\
\hline No & $139(77)$ & $212(86)$ & 1.0 & & 1.0 & - & 1.0 & \\
\hline Yes & $42(23)$ & $34(14)$ & $2.01(1.20-3.35)$ & $0.008^{* \star}$ & $1.69(0.96-2.97)$ & 0.07 & $1.65(0.91-2.97)$ & 0.10 \\
\hline \multicolumn{9}{|l|}{ Sexual abuse $^{\mathrm{d}}$} \\
\hline No & $147(84)$ & $205(87)$ & 1.0 & & 1.0 & & 1.0 & \\
\hline Yes & $29(16)$ & $30(13)$ & $1.28(0.73-2.24)$ & 0.38 & $1.55(0.86-2.82)$ & 0.15 & $1.35(0.71-2.56)$ & 0.36 \\
\hline \multicolumn{9}{|c|}{ Physical and/or sexual abuse ${ }^{d}$} \\
\hline None & $121(69)$ & $183(78)$ & 1.0 & & 1.0 & & 1.0 & \\
\hline One & $40(23)$ & $42(18)$ & $1.48(0.90-2.44)$ & 0.12 & $1.49(0.87-2.53)$ & 0.15 & $1.52(0.86-2.70)$ & 0.15 \\
\hline Both & $15(8)$ & $10(4)$ & $2.19(0.95-5.09)$ & 0.07 & $2.07(0.80-5.34)$ & 0.13 & $1.76(0.67-4.60)$ & 0.25 \\
\hline
\end{tabular}

\section{Childhood trauma, gender and psychosis}

Data for reports of sexual and physical abuse are shown stratified by gender in Table 3. Women in the cases group were approximately three times more likely to report severe physical abuse during childhood than women in the control group $(P<0.01)$. In contrast, there was no evidence of an association in male participants $(P=0.651)$. A likelihood ratio test of the difference in odds ratios between male and female participants indicated an interaction with physical abuse $\left(\chi^{2}=3.79, P=0.052\right)$. The strength of the association between reported physical abuse and psychosis in women was only slightly attenuated after adjustment for age, study centre, ethnicity and parental mental illness $(P=0.068)$.

A similar pattern was evident with regard to sexual abuse. Women in the cases group were more likely to report sexual abuse than women in the control group $(P=0.070)$, whereas there was no evidence of an association in men $(P=0.595)$. A likelihood ratio test of the difference in odds ratios between the genders indicated only a weak interaction with sexual abuse $\left(\chi^{2}=2.09, P=0.148\right)$. When age, study centre and ethnicity were controlled for the association between reported sexual abuse and psychosis in women increased slightly $(P<0.05)$; when parental mental illness was added this difference was no longer statistically significant $(P=0.133)$.

When considering the composite abuse measure, women in the cases group were approximately twice as likely to have reported either sexual or physical abuse $(P<0.01)$ and this association held after adjustment for all confounders $(P<0.01)$. There was no association for men $(P=0.704)$. A likelihood ratio test of the difference in odds ratios between the genders indicated an interaction with reports of sexual or physical abuse $\left(\chi^{2}=4.50\right.$, $P=0.034)$. Further, women who had experienced both sexual and physical abuse were over three times more likely to be cases than controls $(P<0.01)$, which suggests a dose-response effect. However, this association was attenuated following adjustment for age at interview, study centre, ethnicity and parental history of mental illness $(P=0.223)$. There was no significant difference in this composite measure for male cases compared with male controls $(P=0.734)$. No evidence was found for an interaction between gender and reports of both sexual and physical abuse $\left(\chi^{2}=0.65, P=0.419\right)$.

As adverse events in childhood have previously been linked to affective disorders, ${ }^{25}$ the results for female participants were 


\begin{tabular}{|c|c|c|c|c|c|c|c|c|}
\hline Type of abuse & $\begin{array}{l}\text { Cases } \\
n(\%)\end{array}$ & $\begin{array}{c}\text { Controls } \\
n(\%)\end{array}$ & $\begin{array}{c}\text { Unadjusted } \\
\text { OR }^{\mathrm{a}} \\
(95 \% \mathrm{Cl})\end{array}$ & $P$ & $\begin{array}{c}\text { Adjusted } \mathrm{OR}^{\mathrm{a}, \mathrm{b}} \\
(95 \% \mathrm{Cl})\end{array}$ & $P$ & $\begin{array}{c}\text { Adjusted } \mathrm{OR}^{\mathrm{a}, \mathrm{c}} \\
(95 \% \mathrm{Cl})\end{array}$ & $P$ \\
\hline \multicolumn{9}{|l|}{ Physical abuse } \\
\hline Males & $n=97$ & $n=103$ & & & & & & \\
\hline No & $78(80)$ & $85(83)$ & 1.0 & & 1.0 & & 1.0 & \\
\hline Yes & $19(20)$ & $18(17)$ & $1.18(0.57-2.45)$ & 0.65 & $1.28(0.60-2.72)$ & 0.53 & $1.16(0.53-2.56)$ & 0.71 \\
\hline Females & $n=84$ & $n=143$ & & & & & & \\
\hline No & $61(73)$ & $127(89)$ & 1.0 & & 1.0 & & 1.0 & \\
\hline Yes & $23(27)$ & $16(11)$ & $3.33(1.61-6.90)$ & $0.001^{* *}$ & $2.16(0.95-4.93)$ & 0.07 & $2.25(0.94-5.35)$ & 0.07 \\
\hline \multicolumn{9}{|l|}{ Sexual abuse } \\
\hline Males & $n=93$ & $n=100$ & & & & & & \\
\hline No & $86(92)$ & $91(91)$ & 1.0 & & 1.0 & & 1.0 & \\
\hline Yes & 7 (8) & $9(9)$ & $0.76(0.27-2.12)$ & 0.60 & $1.01(0.36-2.82)$ & 0.98 & $0.87(0.31-2.48)$ & 0.80 \\
\hline Females & $n=83$ & $n=135$ & & & & & & \\
\hline No & $61(73)$ & $114(84)$ & 1.0 & & 1.0 & & 1.0 & \\
\hline Yes & $22(27)$ & $21(16)$ & $1.88(0.95-3.72)$ & 0.07 & $2.20(1.03-4.66)$ & $0.04^{*}$ & $1.86(0.83-4.19)$ & 0.13 \\
\hline \multicolumn{9}{|c|}{ Physical and/or sexual abuse } \\
\hline Males & $n=93$ & $n=100$ & & & & & & \\
\hline None & $72(77)$ & $76(76)$ & 1.0 & & 1.0 & & 1.0 & \\
\hline One & 17 (18) & $21(21)$ & $0.87(0.42-1.80)$ & 0.70 & $0.82(0.39-1.71)$ & 0.60 & $0.85(0.39-1.85)$ & 0.68 \\
\hline Both & $4(4)$ & 3 (3) & $1.30(0.28-6.05)$ & 0.73 & $1.99(0.40-10.00)$ & 0.40 & $1.62(0.33-8.01)$ & 0.55 \\
\hline Females & $n=83$ & $n=135$ & & & & & & \\
\hline None & 49 (59) & 107 (79) & 1.0 & & 1.0 & & 1.0 & \\
\hline One & $23(28)$ & $21(16)$ & $2.50(1.24-5.01)$ & $0.01^{*}$ & $2.61(1.22-5.59)$ & $0.01 *$ & $2.59(1.15-5.84)$ & $0.02^{*}$ \\
\hline Both & $11(13)$ & 7 (5) & 3.37 (1.22-9.35) & $0.02^{\star}$ & $2.48(0.78-7.93)$ & 0.13 & $2.12(0.63-7.06)$ & 0.22 \\
\hline
\end{tabular}

further examined by diagnosis. Reports of severe childhood physical abuse were elevated to a similar degree in both women with affective $(\mathrm{OR}=2.88,95 \% \mathrm{CI} 1.35-6.11, P=0.006)$ and with non-affective $(\mathrm{OR}=2.85,95 \% \mathrm{CI} 1.16-7.02, P=0.023)$ diagnoses.

\section{Psychosis-like symptoms}

Within the control sample there were slightly elevated rates of psychosis-like experiences among those with a reported history of severe childhood sexual abuse $(\mathrm{OR}=1.42,95 \%$ CI $0.55-3.65$, $P=0.469)$ or physical abuse (OR=1.71, 95\% CI 0.69-4.21, $P=0.244$ ), but these associations failed to reach significance. Similarly to the trend found for female psychosis cases, women in the control group who reported severe physical abuse in childhood were three times more likely to endorse psychosis-like symptoms than those with no such abuse history $(\mathrm{OR}=3.09$, 95\% CI 0.91-10.53, $P=0.072$ ), but the finding was non-significant owing to the small numbers involved. There was no increased rate of psychosis-like experiences among men for either type of abuse or among women who reported being sexually abused in childhood.

\section{Discussion}

In contrast to some previous research we found no compelling evidence that childhood trauma was associated with risk of psychosis in the full unstratified sample. We did, however, find consistent evidence that women with psychosis were approximately twice as likely to report severe physical or sexual abuse prior to the age of 16 years, independent of several potential confounders, including parental history of mental illness. Notably, the effect of reported physical abuse was somewhat stronger and more robust than that for sexual abuse. There was no evidence that either type of childhood maltreatment was more common in male cases compared with male controls. Our confidence in these gender-specific results for psychotic disorder is enhanced by the finding that women in the control group who reported severe childhood physical abuse also reported elevated rates of psychosis-like symptoms, in keeping with a continuum model of psychosis. ${ }^{22}$ Furthermore, the increased odds ratios for reports of both sexual and physical abuse compared with either type of abuse alone across the sample as a whole are suggestive of a cumulative effect of childhood trauma on development of clinical psychosis, but there is insufficient power to detect whether this is a significant trend.

\section{Strengths and weaknesses}

This is the largest population-based case-control study of early trauma and psychosis yet conducted. Our use of a detailed, validated measure of different forms of childhood abuse, with conservative cut-off points to ensure only the most severe forms of abuse were included, marks a significant advance on previous studies. Further, ours is the first study to investigate gender differences systematically and to compare childhood sexual abuse and physical abuse separately in individuals with psychotic disorder $v$. a non-clinical control group. ${ }^{7}$ However, these findings need to be considered in the light of a number of limitations. One potential limitation of this study is the reliance on the retrospective reporting of abuse. This relates not only to the natural process of forgetting, but also more specifically to the possibility that those with psychosis may have particular memory problems, ${ }^{26}$ or may exaggerate adverse life events in an attempt to understand their illness or as part of their symptomatology. However, reports of abuse by people with psychosis have been shown to be reliable over time and to be as reliable as those of the general population. ${ }^{27}$ Moreover, conducting prospective general population studies may 
yield few cases of psychosis, and questioning a child about recent adverse experiences might cause unnecessary distress that could not be justified in the context of research.

To minimise problems of retrospective reporting in this study a validated tool was employed that involved detailed questions along with the use of conservative cut-off points to capture only severe instances of abuse. ${ }^{15}$ This is important to ensure the validity of the abuse concept by improving the accuracy of recall of maltreatment experiences ${ }^{16}$ and excluding minor forms of physical punishment such as smacking. However, this may have resulted in a slight underestimation of the true abuse rates. Moreover, despite the CECA.Q being more detailed than the majority of instruments previously used with patients with psychosis, in future it would be preferable to employ the full CECA interview as this allows for more extensive assessment of multiple types of abuse experiences at different ages. We also focused on a sample of patients with first-episode psychosis, thus reducing the effects of the disorder on recall compared with previous studies that have predominantly relied on samples of patients with chronic disorder. Furthermore, a preliminary testretest analysis of 20 psychosis cases was conducted for those who had completed the CECA.Q at baseline and 7 years later. The specificity of childhood physical abuse was $83 \%$ whereas childhood sexual abuse yielded $95 \%$ specificity (i.e. proportion of cases reporting abuse at both time points). Therefore, this initial analysis revealed high specificity over time, thus implying minimal levels of false positives in the data included in this paper. This test-retest analysis also confirmed that the CECA.Q could be reliably employed in a psychosis sample.

It is further reassuring to note that the prevalence of sexual abuse reported by the control group ( $16 \%$ in women, $9 \%$ in men) is similar to that found in a recent general population survey in the UK ( $16 \%$ in women, $7 \%$ in men) ${ }^{28}$ The prevalence of physical abuse in our control group (11\% in women, $17 \%$ in men) is also similar to these published UK figures $(12 \%$ in women, $15 \%$ in men). ${ }^{28}$

A further potential limitation is the use of the psychiatric status of biological parents as a proxy for the participants' genotype. This is not a particularly sensitive method, and has been criticised on the basis that offspring share only half of their parents' genetic material and developmental effects may dilute their shared inheritance further. ${ }^{29}$ In order to address this issue comprehensively, specific genes and their polymorphisms need to be investigated. Furthermore, we did not have enough power to investigate other potential mediators or moderators of the association between childhood abuse and psychosis. For instance, social deprivation, ${ }^{30,31}$ substance misuse, ${ }^{32}$ victimisation in adulthood, ${ }^{33,34}$ negative beliefs about the self and others, ${ }^{35}$ and insecure attachment style $\mathrm{e}^{36,37}$ have all been linked to childhood adversity and psychosis, so may potentially have a role in the pathway between the two or at least partially explain the results of this study. Future research should therefore ensure that these factors are fully assessed and that the sample size is adequate to explore the mediating or moderating effects of such variables.

\section{Comparisons with previous research}

Recent research provides an inconsistent set of findings concerning the association between trauma and psychosis. ${ }^{78}$ Some prospective population-based studies suggest strong effects, ${ }^{1,38}$ others suggest much weaker or no effect. ${ }^{39}$ This discrepancy may be related to methodology. There is no consistency in how abuse or psychosis has been measured and our data emphasise the importance of distinguishing between physical and sexual abuse. A further intriguing possibility suggested by our findings is that some of this inconsistency results from a failure to examine potential gender effects. Our data suggest that failure to do this may produce overall effects that obscure important gender differences. However, our findings are similar to those reported by Shevlin et al, ${ }^{3}$ who found that physical abuse produced the most robust association with psychosis-like symptoms as was the case in our diagnosed sample and among our female controls, although the relationship we found was less marked. Indeed, some overlap would be expected as attenuated symptoms and clinical disorder are argued to be on a psychosis continuum. ${ }^{22}$

A recent review summarised the published prevalences of childhood abuse among in-patient samples and found much higher rates than those reported here: for instance, the reported average rates of childhood sexual abuse for female and male patients with a psychotic disorder were $42 \%$ and $28 \%$ respectively, and rates of childhood physical abuse were $35 \%$ and $38 \%$ respectively. ${ }^{8}$ In contrast, in our study female and male reported rates for sexual abuse were $27 \%$ and $8 \%$ respectively, and $27 \%$ and $20 \%$ for physical abuse respectively. This discrepancy might be accounted for by the reliance in previous studies on samples of in-patients with chronic schizophrenia, with high rates of abuse merely reflecting a persistent course of the disorder and poor functional outcome rather than onset of psychosis or its symptoms.

\section{Implications and future research}

Although our results require replication, they do raise intriguing questions concerning potential differences in the impact of early abuse on men and women. One possible explanation for a differential gender outcome following the experience of childhood abuse is that girls are more prone to internalising difficulties they encounter, whereas boys tend to respond by exhibiting externalising behaviour. ${ }^{40}$ In terms of physical abuse both genders may adapt to such a threatening family environment by developing hostile attributions of others' intentions. ${ }^{41}$ Girls may consequently over time distance themselves from others and become overly suspicious of others' intentions and behaviour, leaving them predisposed to psychotic symptoms such as paranoid delusional beliefs and ideas of reference, ${ }^{42}$ whereas boys may display inappropriate or maladaptive behaviours such as aggression, ${ }^{43}$ leaving them vulnerable to developing conduct disorders. Another possibility is that men who have been abused may still develop psychosis but do so while in prison or other forensic settings and could therefore potentially have been missed cases in this study. It is unlikely, however, that there would be a sufficient number of such cases to account for the gender difference found, and prisoners with psychosis are often transferred to secure in-patient wards in the community for treatment and hence most would have been included in this study.

However, it is equally possible that other factors may explain the gender effects observed in our study. For instance, there could be a differential interaction of early trauma with genetic variations and/or hormonal factors, as suggested by animal studies. ${ }^{44}$ Additionally, although we found that controlling for affective diagnosis did not appear to account for the excess rate of reported childhood abuse in women, it is possible that other factors such personality disorder, substance misuse and anxiety, which have been found to correlate with childhood abuse, ${ }^{39}$ might account for the increased female rates. The experience of traumatic events in adulthood has also been linked to psychosis, ${ }^{33}$ and women are more likely than men to be exposed to severe interpersonal traumas during adulthood, such as rape and partner violence. ${ }^{45}$ This higher risk of exposure to retraumatisation in adulthood may potentially account for the gender difference found in this 
study. Unfortunately, we do not have the relevant data to explore this possibility. Women have also been shown to be more likely to appraise traumatic events as threatening and stressful than men, ${ }^{46}$ which may in turn make them more vulnerable to hypothalamicpituitary-adrenal axis dysregulation following exposure to childhood abuse, ${ }^{47}$ and potentially therefore to later developing psychosis. ${ }^{48}$ Furthermore, women have been observed to have a greater need for social support following trauma, ${ }^{49}$ and therefore if this support is lacking or they are unable to seek such support, perhaps owing to their hostile attributions of others and subsequent social isolation, this might also render women more at risk of psychopathology than men faced with similar social environments. ${ }^{50}$ Moreover, the lack of an association in men could be due to underreporting by male participants with psychosis, but it is not clear why they would be less likely to disclose than men in the control group, or in a differential way to female cases compared with female controls. Therefore, it seems unlikely that this could fully account for the non-significant male findings although it remains a possible partial explanation. Alternatively, as the numbers of men in the cases group who reported sexual $(n=7)$ and physical $(n=19)$ abuse were low, it may simply be that this study was underpowered to detect an association in men and these results therefore need to be replicated in a larger sample.

In conclusion, reports of childhood physical abuse were found to be associated with later psychosis, particularly in women. A significant gender interaction was found between psychosis and reports of either physical or sexual abuse, with a more than twofold increase in reported rates among women which held after adjustment for a range of confounders. The reason for these gender-specific results is unclear and requires further investigation along with potential interactions with other risk factors. If replicated, these findings not only have potentially important implications for furthering our understanding of the potential aetiology of psychosis, but also for the development of genderspecific interventions for abused children to prevent later mental health and behavioural problems.

Helen Fisher, MSC, Division of Psychological Medicine and Psychiatry, Institute of Psychiatry, and MRC Social, Genetic and Developmental Psychiatry Centre, Institute of Psychiatry; Craig Morgan, PhD, Health Service and Population Research Department, Institute of Psychiatry: Paola Dazzan, MRCPsych, Thomas K. Craig FRCPsych, Kevin Morgan, PhD, Division of Psychological Medicine and Psychiatry, Institute of Psychiatry, King's College London, UK; Gerard Hutchinson, MRCPsych, Psychiatry Unit, Faculty of Medical Sciences, University of the West Indies, St Augustine, Trinidad, Trinidad \& Tobago; Peter B. Jones, FRCPsych, Department of Psychiatry, University of Cambridge, Addenbrooke's Hospital, Cambridge; Gillian A. Doody, FRCPsych, Division of Psychiatry, University of Nottingham; Carmine Pariante, MRCPsych, Division of Psychological Medicine and Psychiatry, Institute of Psychiatry; Peter McGuffin, FRCPsych, MRC Social, Genetic and Developmental Psychiatry Centre, Institute of Psychiatry; Robin M. Murray, FRCPsych, Julian Leff Psychiatry Centre, Institute of Psychiatry; Robin M. Murray, FRCPsych, Julian
FRCPsych, Paul Fearon, MRCPsych, Division of Psychological Medicine and Psychiatry, Institute of Psychiatry, King's College London, London, UK

Correspondence: Helen Fisher, PO 80, Social, Genetic and Developmental Psychiatry Centre, Institute of Psychiatry, King's College London, De Crespigny Park, London SE5 8AF, UK. Email: h.fisher@iop.kcl.ac.uk

First received 21 Nov 2007, final revision 3 Jul 2008, accepted 6 Aug 2008

\section{Funding}

The ESOP study was funded by the UK Medical Research Council (MRC) and the Stanley Medical Research Institute. H.F is jointly funded by the Economic and Social Research Council and the MRC.

\section{Acknowledgements}

We thank all staff members and students past and present who were involved in the $\mathbb{E}$ SOP study. We are also indebted to all individuals who participated in the study and were essential for its successful completion.

\section{References}

1 Bebbington PE, Bhugra D, Brugha T, Singleton N, Farrell M, Jenkins R, Lewis G, Meltzer $\mathrm{H}$. Psychosis, victimisation and childhood disadvantage: evidence from the second British National Survey of Psychiatric Morbidity. $\mathrm{Br} J$ Psychiatry 2004; 185: 220-6.

2 Janssen I, Krabbendam L, Bak M, Hanssen M, Vollebergh W, de Graaf R, et al. Childhood abuse as a risk factor for psychotic experiences. Acta Psychiatr Scand 2004; 109: 38-45.

3 Shevlin M, Dorahy MJ, Adamson G. Trauma and psychosis: an analysis of the National Comorbidity Survey. Am J Psychiatry 2007; 164: 166-9.

4 Neria Y, Bromet EJ, Sievers S, Lavelle J, Fochtmann LJ. Trauma exposure and post-traumatic stress disorder in psychosis: findings from a first admission cohort. J Consult Clin Psychol 2002; 70: 246-51.

5 Spence W, Mulholland C, Lynch G, McHugh S, Dempster M, Shannon C. Rates of childhood trauma in a sample of patients with schizophrenia as compared with a sample of patients with non-psychotic psychiatric diagnoses. J Trauma Dissociation 2006; 7: 7-22.

6 Read J, van Os J, Morrison AP, Ross CA. Childhood trauma, psychosis and schizophrenia: a literature review with theoretical and clinical implications. Acta Psychiatr Scand 2005; 112: 330-50.

7 Bendall S, Jackson HJ, Hulbert CA, McGorry PD. Childhood trauma and psychotic disorders: a systematic, critical review of the evidence. Schizophr Bull 2008; 34: 568-79.

8 Morgan C, Fisher H. Environment and schizophrenia: environmental factors in schizophrenia: childhood trauma - a critical review. Schizophr Bull 2007; 33: 3-10.

9 Haatainen KM, Tanskanen A, Kylma J, Honkalampi K, Koivumaa-Honkanen $\mathrm{H}$, Hintikka J, et al. Gender differences in the association of adult hopelessness with adverse childhood experiences. Soc Psychiatry Psychiatr Epidemiol 2003; 38: 12-7

10 Hyman SM, Garcia M, Sinha R. Gender specific associations between types of childhood maltreatment and the onset, escalation and severity of substance use in cocaine dependent adults. Am J Drug Alcohol Abuse 2006; 32: 655-64.

11 Morgan C, Dazzan P, Morgan K, Jones P, Harrison G, Leff J, et al. First episode psychosis and ethnicity: initial findings from the AESOP study. World Psychiatry 2006; 5: 40-6.

12 World Health Organization. The ICD-10 Classification of Mental and Behavioural Disorders: Clinical Descriptions and Diagnostic Guidelines. WHO, 1992.

13 Jenkins R, Meltzer $\mathrm{H}$. The national survey of psychiatric morbidity in Great Britain. Soc Psychiatry Psychiatr Epidemiol 1995; 30: 1-4.

14 Bebbington $\mathrm{P}$, Nayani T. The Psychosis Screening Questionnaire. Int J Methods Psychiatr Res 1995; 5: 11-20.

15 Bifulco A, Bernazzani O, Moran PM, Jacobs C. The Childhood Experiences of Care and Abuse Questionnaire (CECA.Q) - validation in a community series. Br J Clin Psychol 2005; 44: 563-81.

16 Prescott A, Bank L, Reid JB, Knutson JF, Burraston BO, Eddy JM. The veridicality of punitive childhood experiences reported by adolescents and young adults. Child Abuse Negl 2000; 24: 411-23.

17 Smith N, Lam D, Bifulco A, Checkley S. Childhood Experience of Care and Abuse Questionnaire (CECA.Q): validation of a screening instrument for childhood adversity in clinical populations. Soc Psychiatry Psychiatr Epidemiol 2002; 37: 572-9.

18 Mallett R, Leff J, Bhugra D, Pang D, Zhao JH. Social environment, ethnicity and schizophrenia. SOC Psychiatry Psychiatr Epidemiol 2002; 37: 329-35.

19 National Institute of Mental Health. FIGS Face Sheet (http://zork.wustl.edu/ nimh/figs/FIGS.pdf). NIMH, 1999.

20 World Health Organization. Schedules for the Clinical Assessment of Neuropsychiatry. WHO, 1994

21 Kirkbride J, Fearon P, Morgan C, Dazzan P, Morgan K, Tarrant J, et al. Heterogeneity in incidence rates of schizophrenia and other psychotic syndromes: findings from the 3-center AeSOP study. Arch Gen Psychiatry 2006; 63: 250-8.

22 Johns LC, Cannon M, Singleton N, Murray RM, Farrell M, Brugha $T$, et al. Prevalence and correlates of self-reported psychotic symptoms in the British population. Br J Psychiatry 2004; 185: 298-305.

23 Morgan C, Kirkbride J, Leff J, Craig T, Hutchinson G, McKenzie K, et al. Parental separation, loss and psychosis in different ethnic groups: a case-control study. Psychol Med 2007; 37: 495-503.

24 Taylor CG, Norman J, Murphy M, Jellinek M, Quinn D, Poitrast FG, et al. Diagnosed intellectual and emotional impairment among parents who seriously mistreat their children: prevalence, type and outcome in a court sample. Child Abuse Negl 1991; 15: 389-401. 
25 Bifulco A, Brown GW, Adler Z. Early sexual abuse and clinical depression in adult life. Br J Psychiatry 1991; 159: 115-22.

26 Saykin AJ, Gur RC, Gur RE, Mozley PD, Mozely LH, Resnick SM, et al. Neuropsychological functioning in schizophrenia: selective impairment in memory and learning. Arch Gen Psychiatry 1991; 48: 618-24.

27 Darves-Bornoz JM, Lemperiere T, Degiovanni A, Gaillard P. Sexual victimisation in women with schizophrenia and bipolar disorder. Soc Psychiatry Psychiatr Epidemiol 1995; 30: 78-84.

28 May-Chahal C, Cawson P. Measuring child maltreatment in the United Kingdom: a study of the prevalence of child abuse and neglect. Child Abuse Negl 2005; 29: 969-84.

29 Plomin R. Genetics and Experience: The Interplay between Nature and Nurture. Sage, 1994

30 Croudace TJ, Kayne R, Jones PB, Harrison GL. Non-linear relationship between an index of social deprivation, psychiatric admission prevalence and the incidence of psychosis. Psychol Med 2000; 30: 177-85.

31 Sidebotham $\mathrm{P}$, Heron J, ALSPAC Study Team. Child maltreatment in the 'children of the nineties': a cohort study of risk factors. Child Abuse Negl 2006; 30: 497-522.

32 Houston JE, Murphy J, Adamson G, Stringer M, Shevlin M. Childhood sexual abuse, early cannabis use, and psychosis: testing an interaction model based on the National Comorbidity Survey. Schizophr Bull 2008; 34: 580-5.

33 Bebbington $\mathrm{P}$, Wilkins $\mathrm{S}$, Jones $\mathrm{P}$, Foerster A, Murray R, Toone B, et al. Life events and psychosis. Initial results from the Camberwell Collaborative Psychosis Study. Br J Psychiatry 1993; 162: 72-9.

34 Desai S, Arias I, Thompson MP, Basile KC. Childhood victimization and subsequent adult revictimization assessed in a nationally representative sample of women and men. Violence vict 2002; 17: 639-53.

35 Gracie A, Freeman D, Green S, Garety PA, Kuipers E, Hardy A, et al. The association between traumatic experience, paranoia and hallucinations: a test of the predictions of psychological models. Acta Psychiatr Scand 2007; 116: $280-9$.

36 Berry K, Barrowclough C, Wearden A. A review of the role of adult attachment style in psychosis: unexplored issues and questions for further research. Clin Psychol Rev 2007; 27: 458-75.

37 Bifulco A, Kwon J, Jacobs C, Moran PM, Bunn A, Beer N. Adult attachment style as mediator between childhood neglect/abuse and adult depression and anxiety. Soc Psychiatry Psychiatr Epidemiol 2006; 41: 796-805.
38 Whitfield C, Dube S, Felitti V, Anda R. Adverse childhood experiences and hallucinations. Child Abuse Negl 2005; 29: 797-810.

39 Spataro J, Mullen PE, Burgess PM, Wells DL, Moss SA. Impact of child sexual abuse on mental health: prospective study in males and females. $\mathrm{Br} \mathrm{J}$ Psychiatry 2004; 184: 416-21.

40 McFadyen-Ketchum SA, Bates JE, Dodge KA, Pettit GS. Patterns of change in early childhood aggressive-disruptive behaviour: gender differences in predictions from early coercive and affectionate mother-child interactions. Child Dev 1996; 67: 2417-33.

41 Dodge KA, Pettit GS, McClaskey CL, Brown M. Social competence in children. Monogr Soc Res Child Dev 1986; 51 (2, Serial No. 213).

42 Frith CD. The Cognitive Neuropsychology of Schizophrenia. Psychology Press, 1992.

43 Eisenberg N, Fabes RA, Nyman M. Bernzweig J, Pinuelas A. The relations of emotionality and regulation to children's anger-related reactions. Child Dev 1994; 65: 109-28.

44 Barr CS, Newman TK, Schwandt M, Shannon C, Dvoskin RL, Lindell SG, et al. Sexual dichotomy of an interaction between early adversity and the serotonin transporter gene promoter variant in rhesus macaques. Proc Natl Acad Sci USA 2004; 101: 12358-63.

45 Kessler RC, Sonnega A, Bromet E, Hughes M, Nelson CB. Posttraumatic stress disorder in the National Comorbidity Survey. Arch Gen Psychiatry 1995; 52: 1048-60.

46 Cole T, Sapp GL. Stress, locus of control, and achievement of high school seniors. Psychol Rep 1988; 63: 355-9.

47 De Bellis MD, Chrousos GP, Dorn LD, Burke L, Helmers K, Kling MA, et al. Hypothalamic-pituitary-adrenal axis dysregulation in sexually abused girls. J Clin Endocrin Metabol 1994; 78: 249-55.

48 Moore $H$, West AR, Grace AA. The regulation of forebrain dopamine transmission: relevance to the pathophysiology and psychopathology of schizophrenia. Biol Psychiatry 1999; 46: 40-55.

49 Andrews B, Brewin CR, Rose S. Gender, social support, and PTSD in victims of violent crime. J Trauma Stress 2003; 16: 421-7.

50 Ahern J, Galea S, Fernandez WG, Koci B, Waldman R, Vlahov D. Gender, social support, and posttraumatic stress in postwar Kosovo. J Nerv Ment Dis 2004; 192: 762-70.

\section{Catatonia}

Catatonia, a motor dysregulation syndrome, was described by Karl Kahlbaum in 1874. Emil Kraepelin buried catatonia in schizophrenia, where it has been ignored for more than a century. When looked for today, catatonia is found in $10 \%$ of acute psychiatric admissions, most often in persons with mood disorder or toxicity. Catatonia is readily diagnosable, verifiable by a lorazepam challenge test, and eminently and rapidly treatable even in its lethal forms, with lorazepam or electroconvulsive therapy. Prompt recognition and treatment saves lives. It is time to bury schizophrenia, catatonic type and resurrect catatonia into its own home in the psychiatric classification. 